\title{
Trigeminal Neuralgia: A Comparison of the Results of Percutaneous Rhizotomy and Microvascular Decompression
}

\author{
G.G. FERGUSON, D.C. BRETT. S.J. PEERLESS. H.W.K. BARR \\ and J.P. GIRVIN
}

SUMMARY: Seventy-five patients were treated between March 1976 and June 1980 for classical idiopathic tic douloureux. Fifty-five patients underwent percutaneous trigeminal rhizotomy (PTR) and wentyfour had posterior fossa microvascular decompression (MVD) of the trigeminal nerve. Four patients had both procedures. In the PTR group. $4 \%$ were immediate failures, $42 \%$ had a delayed recurrence of pain, while $54 \%$ remained tolally pain free with an average follow-up of 30 months. In the MVD group, $12 \%$ were immediate failures, $17 \%$ had a delayed recurrence of

RÉSUMÉ: De mars 1976 à juin 1980 nous avons traité 75 patients pour tic douloureux idiopathique classique. Chez 55 patients nous avons pratiqué une rhizotomie perculanée du trijumeau (groupe PTR) et chez 24 une décompression microvasculaire du nerf dans la fosse postérieure (groupe $M V D) .4$ patients subirent les deux procédures. Dans le groupe PTR, $4 \%$ s'avérèrent des échecs immédiats; $42 \%$ virent la douleur reprendre après un délai; $54 \%$ restent totalement libres de douleur pour une période moyenne de 30 mois. Dans le groupe $M V D,{ }^{\cdots}$ furent des échecs immédiats; $17 \%$ i.....t la douleur pain, and $7 / \%$ have remained free of pain with an average follow-up of 28 months. Neither procedure can be regarded as ideal surgical treatment for patients with pain refractory to medical treatment. Percutaneous rhizotom! has ... ssablished place because of its safely, $p$ cularly in elderly. patients. $A$ high rate of recurrent pain is to be expected. Microvascular decompression has appeal in younger patients because of its non-destructive nature but the long term efficacy of the procedure is not know'n.

reprendre éventuellement; $71 \%$ furent libres de douleur pour une période movenne de 28 mois. Nous ne pouvons considérer ces procédures comme traitement idéal pour les patients dont la douleur est réfractaire au traitement médical. La rhizotomie percutanée est un traitement établi surtout à cause de sa sécurité chez les patients âgés. mais un raux élevé de rechute doit être prévu. Chez les patients plus jeunes nous choisissons la décompression microvasculaire parce qu'elle est non destructive, mais nous ne connaissons pas encore son efficacité à long terme.

\section{INTRODUCTION}

The pathogenesis of idiopathic trigeminal neuralgia (tic douloureux) remains uncertain. Its surgical treatment, largely a history of discarded procedures, is controversial. Two procedures are currently popular for the management of those patients failing to obtain satisfactory pain relief with medical treatment: percutaneous trigeminal rhizotomy and microvascular decompression of the trigeminal nerve in the posterior fossa.

The modern technique of percutaneous thermocoagulation of the trigeminal ganglion and rootlets (Sweet and Wepsic, 1974) is widely practised because of its remarkable safety and its suitability for elderly patients, and patients who are poor risks for major surgery.

Dandy (1934) was the first to report an association between vascular compression of the trigeminal sensory root and tic douloureux. More recently, Jannetta (1976) has proposed that all cases not secondary to neoplasms, aneurysms or multiple sclerosis are the result of vascular cross-compression at the trigeminal root entry zone by an exaggerated caudal loop of the superior cerebellar artery or less commonly, a loop of the anterior inferior cerebellar artery, a vein, or both. He further proposes that the definitive treatment is to identify the offending vessel at surgery, and to separate it permanently from the nerve by means of a prosthetic implant. This microvascular decompression is reported to produce lasting relief of pain without facial numbness. There are no reports of the longer term results of this procedure other than by Jannetta.

We are reporting our experience with these two procedures in a group 
of patients in whom the follow-up is complete. Four of the authors have contributed their cases of microvascular decompression, while the percutaneous rhizotomies have been carried out by one surgeon (GGF).

\section{CLINICAL MATERIAL}

Seventy-five patients were treated between March 1976 and June 1980 (Table 1). Four patients underwent both procedures during that time. None of the patients had atypical facial pain or pain secondary to malignancy. All the patients were intolerant of or refractory to medical therapy with carbamazepine or phenytoin. Prior surgical treatment in many of the patients (Table 2), and subsequently repeated medical therapy, had failed to prevent severe recurrence, including one patient who had undergone microvascular decompression at another centre.

The posterior fossa procedure was not offered to patients over the age of seventy or patients considered poor risks. Eight patients with trigeminal neuralgia secondary to multiple sclerosis, diagnosed pre-operatively, were not considered for microvascular decompression.

TABLE 1

Clinical Characteristics of 75 Patients With Trigeminal Neuralgia

\section{CHARACTERISTIC}

Number of Patients*

Male/Female

Average Age

Average Duration

of Symptoms

with Pain $V_{2}$

$\mathrm{V}_{3}$

$V_{2,3}$

Average Post-Op

Stay

* Four patients underwent both procedures.
Division Involved

\section{PERCUTANEOUS} RHIZOTOMY

55
$22 / 33$
65 years
$(45-86$ yrs.
8 years
$(1$ mo. -40 yrs.)
13
22
5
14
1 day

TABLE 2

Prior Surgical Treatment in 75 Patients With Trigeminal Neuralgia

\section{PROCEDURE}

PERCUTANEOUS RHIZOTOMY

Peripheral nerve

- alcohol injection

- avulsion

\begin{tabular}{c}
11 \\
14 \\
5 \\
1 \\
- \\
2 \\
\hline 32
\end{tabular}

MICROVASCULAR DECOMPRESSION

24
$9 / 15$
52 years
$(30-70$ yrs. $)$
6 years
(6 mos. -17 yrs. $)$
7
11
0
6
8 days

MICROVASCULAR DECOMPRESSION

Subtemporal

- compression

- nerve section

Percutaneous rhizotomy

Microvascular decompression

Total Number of Patients
PERCUTANEOUS TRIGEMINAL RHIZOTOMY - 55 patients

\section{a) Method}

The method described by Sweet and Wepsic (1974) was employed in 55 patients (58 procedures). Fluoroscopy with image intensification was utilized during the initial electrode placement. A 20-guage insulated electrode with a 5 mm non-insulated tip was used to treat pain in a single division; an electrode with a $10 \mathrm{~mm}$ bare tip was used to treat pain in two divisions. The Owl Universal RF System (Owl Instruments Ltd., Downsview, Ontario) provided stimulating and lesion making capability. Short acting barbiturate anaesthesia was given during electrode insertion and the stepwise making of the lesion. The desired result was analgesia in the trigger zone and painful division or divisions with partial preservation of touch. Because of a rapidly resolving sensory loss, the procedure was repeated during the same hospital admission in three patients. The usual post-operative stay was one day.

\section{b) Results (Table 3)}

In general, third division lesions were most easily and accurately made. Satisfactory lesions confined to the second division were more difficult. Failure to obtain adequate analgesia with the first procedure and reluctance of the patient to undergo repeat rhizotomy resulted in failure to obtain initial relief in two patients with second division pain. Both have remained pain free with alcohol injection of the infraorbital nerve. Delayed recurrence of pain from one to 50 months post-operatively has occurred in 23 patients $(42 \%)$. In 13 cases, the recurrence is mild, requiring no treatment to date. Four patients with moderately severe pain require medical therapy. Six patients with severe recurrence have required further surgery. Three underwent microvascular decompression and are included in the description of those cases, while three had alcohol injection of the infraorbital nerve. Thirty patients $(55 \%)$ have remained totally free of pain since the procedure. The average follow-up for the entire group of 55 patients is 30 months. Seven of 
eight patients with trigeminal neuralgia secondary to multiple sclerosis have remained free of pain (Brett et al, 1981).

\section{c) Complications (Table 4)}

There was no mortality and neurological deficit has been confined to the trigeminal nerve. There have been no lasting complaints of troublesome numbness or dysaesthesiae. Anaesthesia dolorosa occurred in one patient, a 78year-old woman who underwent three procedures for intractable first and second division pain, with total anaesthesia as a result. Corneal anaesthesia occurred in four patients, but fortunately neuroparalytic keratitis has not been seen. Asymptomatic motor root involvement demonstrable on jaw opening occurred in 16 patients, and resolved over six months in six cases.

\section{MICROVASCULAR DECOMPRESSION} - 24 patients

\section{a) Method}

The superolateral cerebellar approach to the trigeminal nerve through a retromastoid craniectomy as described by Jannetta (1976) with the patient in the semiprone ("parkbench") position has been used. This positioning eliminates the risk of clinically significant air embolism, and allows
TABLE 3

Results of 79 Procedures in Patients With Trigeminal Neuralgia

\section{RESULT}

Number of Patients

Immediate Failure

Delayed Recurrence

\section{Mild \\ Moderate}

Severe

Pain Free

Average Length of Follow-up

\section{PERCUTANEOUS RHIZOTOMY}

55
$2(4 \%)$
$23(42 \%)$
$(1-50$ mos.)
13
4
6
$30(54 \%)$
30 months
$(2-52$ mos.)

\section{MICROVASCULAR DECOMPRESSION}

$$
\begin{gathered}
24 \\
3(12 \%) \\
4(17 \%) \\
(1-36 \text { mos. }) \\
2 \\
2 \\
- \\
17(71 \%) \\
28 \text { months } \\
(5-44 \text { mos. })
\end{gathered}
$$

exploration of the posterior fossa course of the trigeminal nerve from the pons to the petrous ridge under the operating microscope with minimal retraction of the cerebellar hemisphere. All the patients had skull $x$-rays and computerized tomography preoperatively, but routine angiography was not done. Any vascular compression or distortion of the nerve was identified, the offending vessel was carefully mobilized and then permanently separated from the nerve by an appropriately fashioned piece of Dacron felt. Gelfoam, polyvinyl chloride sponge or muscle were not used. The average post-operative hospital stay was eight days.

\section{b) Operative Findings (Table 5)}

Vascular compression of a convincing nature was found in $22 / 24$ cases. This includes one patient known to have a large, contralateral cerebellar hemispheric arteriovenous malformation (AVM) who was found to have a small AVM surrounding the symptomatic trigeminal nerve with a large draining vein that was causing compression. An unsuspected $1 \mathrm{~cm}$ cholesteatoma was found compressing the trigeminal nerve near the root entry zone in one patient presenting with completely typical "tic" of eight years duration. In one patient, a convincing abnormality could not be found. Our findings are not significantly different from those

TABLE 4

Complications of Percutaneous Trigeminal Rhizotomy

\section{AUTHOR}

Sweet and Wepsic (1974)

Nugent and Berry (1974)

Turnbull (1974)

Onofrio (1975)

Siegfried (1977)

Tew and Keller (1977)

Apfelbaum (1977)

Present Report
274

65

41

140

500

400

48

55
ANAESTHESIA

DOLOROSA/

SEVERE

DYSESTHESIA

CORNEAL ANAESTHESIA

MOTOR

INJURY

$3 \%$
$5 \%$
$12 \%$
$1 \%$
$5 \%$
$19 \%$
$13 \%$
$2 \%$

$10 \%$

$0.4 \%$

$53 \%$

$8 \%$

$22 \%$

$7 \%$

$10 \%$

$15 \%$

$7 \%$

\section{-}

$5 \%$

$1 \%$

$1.4 \%$

$2 \%$

$0 \%$

$0 \%$
$12 \%$

$22 \%$

$40 \%$

$30 \%$

$22 \%$

$2 \%$

$28 \%$ 
TABLE 5

Operative Findings in Patients Undergoing Microvascular Decompression

$\begin{array}{ccc}\text { APFELBAUM } & \text { JANNETTA AND } & \text { PRESENT } \\ \text { (1977) } & \text { ZORUB (1979) } & \text { REPORT }\end{array}$

$\begin{array}{lrrr}\text { Number of Patients } & 55 & 161 & 24 \\ \text { Vascular Compression } & & & 12 \\ \text { Arterial } & 35 & 100 & 5 \\ \text { Venous } & 13 & 19 & 4 \\ \text { Both } & 7 & 22 & 1 \\ \text { AVM } & 0 & 0 & 141 \\ & 55 & 13 & 1 \\ \text { Tumor Compression } & 0 & 6 & 1 \\ \text { No Pathology } & 0 & & 22\end{array}$

TABLE 6

Complications of Microvascular Decompression

$\begin{array}{ccc}\text { APFELBAUM } & \text { JANNETTA AND } & \text { JANNETTA } \\ (1977) & \text { ZORUB (1979) } & (1979)\end{array}$

PRESENT REPORT

Number of Procedures
Mortality
Cerebellar Hematoma
Cerebellar Infarction
Gait Ataxia/Vertigo
Cranial Nerve
Dysfunction $4 \mathrm{th}$
$5 \mathrm{th}$
$7 \mathrm{th}$
$8 \mathrm{th}$
Wound Infection/
Meningitis

55
0
0
0
2
2
0
1
3

161
1
5
4
-

$\begin{array}{cr}465 & 24 \\ 4 & 0 \\ - & 1 \\ - & 0 \\ - & 3\end{array}$

$\begin{array}{ccc}- & 1 & 1 \\ - & - & 1 \\ - & 4 & 2 \\ 14 & 4 & 0\end{array}$

reported in the two largest series published to date in which surgical findings are detailed (Apfelbaum, 1977; Jannetta and Zorub, 1979). Although Apfelbaum (1977) reported no instances of failure to find an abnormality, he has since had negative explorations in $3.5 \%$ of 200 cases (Apfelbaum, personal communication).

Figure 1 illustrates the findings in the patients operated upon by one of the authors (GGF); sketches having been made at the time of the surgery. Convincing cross-compression, most often with visible grooving, occasionally of dramatic degree, was found in every one of these cases except one, J.T., who had a vein approaching but not visibly compressing the nerve distally. She was never totally relieved relieved of pain post-operatively, and ultimately had two percutaneous rhizotomies without lasting benefit. She was re-explored. The prosthetic implant was in place but an artery was found grooving the nerve immediately adjacent to the pons which had either been missed at the first operation or had developed since. Jannetta (1977) has mentioned both possibilities as cause for recurrence or initial failure. Her sensory root was sectioned over $90 \%$ of its extent, and she has been totally relieved of pain for the first time.

\section{c) Results (Table 3)}

Three patients failed to obtain complete relief of pain immediately following the procedure, although their pain was initially improved. Two of these patients, detailed above, have required further surgical treatment for their pain; while the third requires large doses of Tegretol. Four patients have had a delayed recurrence of pain (at 1, 18, 35, and 36 months). These recurrences did not onset with sudden and extreme severity, but rather the pain progressively worsened as is observed characteristically after other types of failed treatment. In two cases, the pain is mild and has required no further treatment to date. In the other two cases, the pain has required medical treatment. All four patients with delayed recurrence of pain had convincing vascular cross-compression. One of these cases was the only patient with an unexplained pre-operative trigeminal sensory deficit. Facial sensation was intact post-operatively and has remained so despite the recurrence of pain. Seventeen patients (71\%) have remained totally free of pain since surgery. The time of followup in these 24 patients ranges from 5 to 44 months (average 28 months).

\section{d) Complications (Table 6)}

Complications in our series have been for the most part relatively minor and transient. There was no mortality. Air embolism during surgery was not encountered. One patient with a postoperative wound infection who developed limb ataxia underwent reoperation for what was feared to be a 
$V_{3}$ TIC
L.S
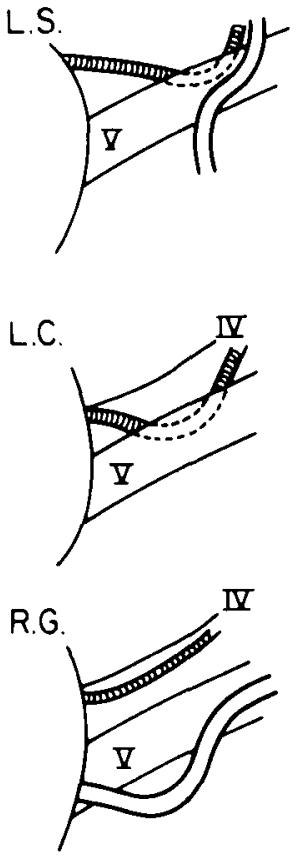
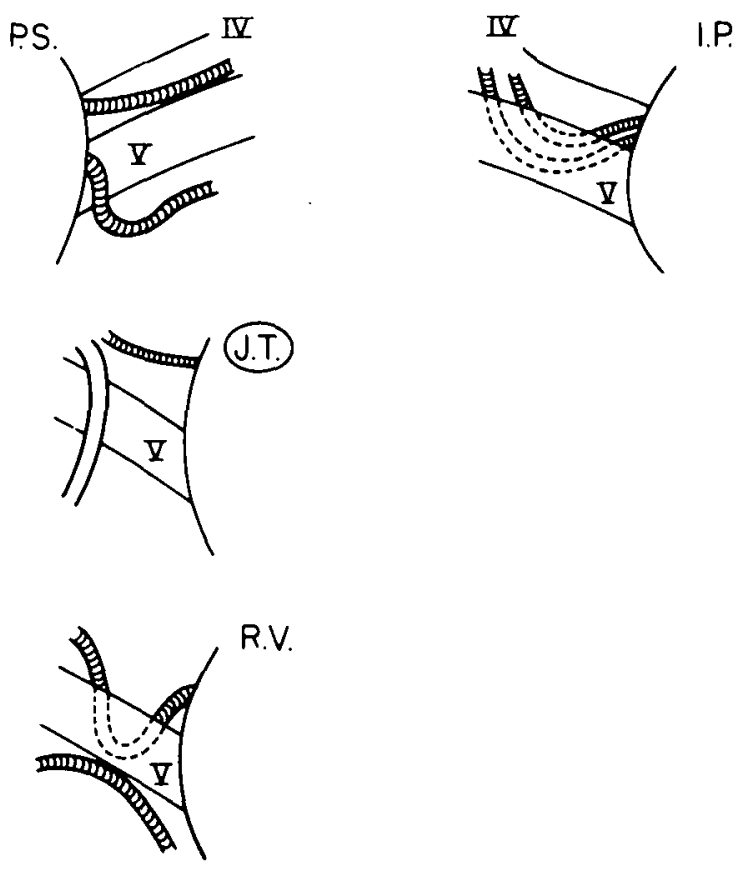

$V_{2}$ TIC

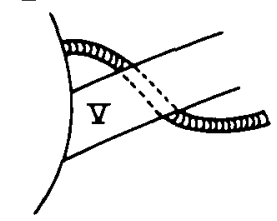

P.C

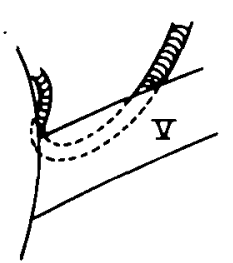

F.B.
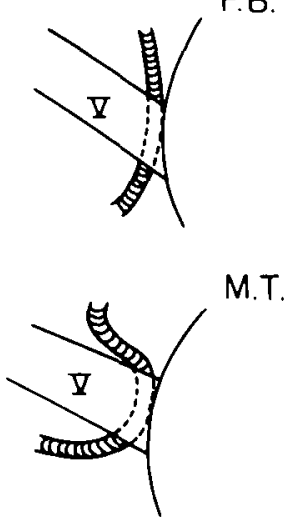

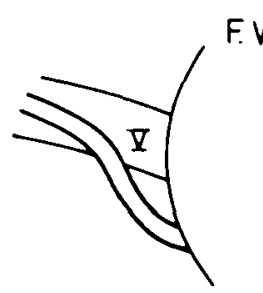
F.W.

$V_{2,3}$ TIC
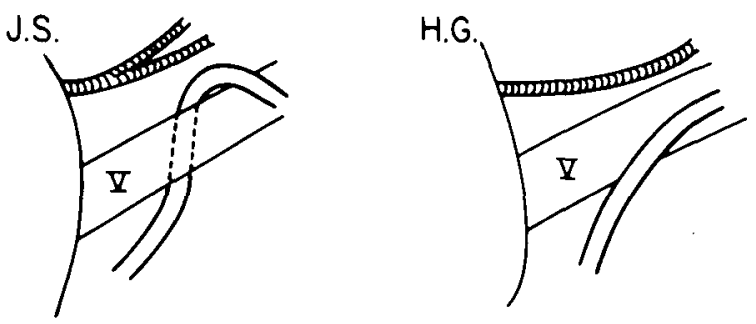

Figure 1- Line drawings of the operative findings in 14 patients undergoing microvascular decompression, grouped by the division involved with pain. Arteries are indicated by hatch marks, while veins are without hatch marks. Right-sided cases have the trigeminal nerve projecting to the right, while in left-sided cases it projects to the left. The circled cases were never completely pain free post-operatively and eventually required further surgical treatment. cerebellar abscess but proved to be a small cerebellar hematoma. Recovery was ultimately complete. Three patients experienced gait ataxia and vertigo. In two, it was transient, clearing within a few weeks, but one patient continues to complain of intermittent unsteadiness. One patient had diplopia lasting two months from an ipsilateral fourth nerve paresis undoubtedly the result of gentle, but unavoidable, manipulation of the nerve which was immediately adjacent to the trigeminal nerve. One other patient has mild but persisting third division numbness. Two patients developed facial weakness which has improved significantly but not completely. In one, this was associated with manipulation during removal of a cholesteatoma; in the other, weakness came on suddenly one week postoperatively in relation to a severe herpes simplex eruption. Three patients had transient conductive hearing loss secondary to fluid in the middle ear from opening the mastoid air cells at surgery. Severe postoperative headache and vomiting of a few days duration was common.

\section{DISCUSSION}

Percutaneous trigeminal rhizotomy by stepwise, temperature-regulated, selective coagulation of the Gasserian ganglion and its rootlets has largely replaced other ablative procedures in the treatment of tic douloureux refractory to medical treatment. Patient satisfaction with the procedure is high (Tew, 1977). Most series report no mortality associated with the procedure and few complications beyond those relating to trigeminal nerve dysfunction (Table 4). A low incidence of extraocular motor palsy (Onofrio, 1974; Siegfried, 1977; Sweet, 1976; Tew and Keller, 1977), intracerebral hematoma (Apfelbaum, 1977), temporal lobe abscess (Apfelbaum, 1977; Sweet, 1976), aseptic meningitis (Sweet, 1976), and inadvertent carotid artery puncture (Nugent and Berry, 1974; Sweet, 1976) have been reported. The commonest complaint following the procedure is unpleasant numbness. This is most likely to occur with a relatively severe 
sensory loss, or sensory loss involving the first division and cornea. Anaesthesia dolorosa is not to be expected unless the sensory denervation is extreme. The risk of unpleasant sensation is minimized by avoiding, if at all possible, dense anaesthetic lesions, particularly in the first division. Corneal anaesthesia has been produced in $10-20 \%$ of reported cases, but the incidence of neuroparalytic keratitis has been low. Trigeminal motor root dysfunction is common, but often not noticed by the patient. Precise localization of the lesion may be a problem. Localized third division lesions are most easily made. Discrete first and second division lesions are often difficult to achieve. A $3 \mathrm{~mm}$ electrode that can be bent may allow more accurate positioning and lesion making (Nugent and Berry, 1974).

Percutaneous rhizotomy has a high initial success rate (Table 7), especially when patients with an immediate recurrence due to an inadequate lesion are re-treated. Failure to penetrate the foramen ovale due to a pterygo-alar bar has been reported (Nugent and Berry, 1974; Apfelbaum, 1977). However, it appears that the procedure has a relatively high rate of pain recurrence, which increases the longer the follow-up. We have the highest recurrence rate reported to date $(42 \%)$, although the majority of our recurrences have been mild requiring neither medical nor surgical treatment. Recurrence appears to relate to the density and accuracy of the initial lesion, and to fading of numbness with time. Long term results of the modern procedure have yet to be reported, but the experience of Menzel et al (1975) in the long term follow-up of patients treated by the original Kirschner technique (Kirschner, 1942) suggests that the majority of patients will have recurrence of their pain eventually.

Microvascular decompression of the trigeminal nerve in the posterior fossa proposed by Jannetta (1976, 1977,1979 ) as a definitive treatment for idiopathic tic douloureux has appeal, particularly in the management of relatively young and otherwise healthy patients. The procedure is non-destructive, directed at an apparent cause of the disorder, and offers the potential of life-long relief from pain without loss of trigeminal function. Concerns have been raised, however, in relation to the posssibility that the observed vascular compression is a coincidental finding (Hardy and Rhoton, 1978) and that the relative risk of the procedure and uncertainty about long term results make it unjustified (Morley, 1977).

Our findings and the reports of others (Tables 5 and 8) support the idea that there is a strong relationship between vascular or other compression of the trigeminal sensory root at or near its root entry zone and tic douloureux. Such compressive lesions have been found in over $95 \%$ of cases. Whether such lesions are the cause of the pain is not absolutely certain, although the hypothesis seems reason- able. Confidence in the concept will undoubtedly be strengthened if favourable long term results from decompression are reported. Although Dandy (1934) only recognized vascular impingement in $45 \%$ of 215 cases of tic douloureux treated by posterior fossa sensory rhizotomy, he firmly believed that this was the cause of the pain in such cases. That a tumor, aneurysm, or AVM compressing the trigeminal sensory root may cause typical tic-like pain has never been questioned. In view of the modern day microsurgical findings regarding vascular compression, Jannetta's generalization of Dandy's observation would appear to be justified. Haines et al (1980) reported a low incidence of vascular compression in an autopsy study of trigeminal nerves of individuals known to be free of facial pain, although Hardy and Rhoton (1978) found vascular contact in approximately $50 \%$ of similar cases examined at autopsy. It appears that when vascular compression occurs it is usually by an elongated caudal loop of the superior cerebellar artery, and less frequently by the anterior inferior cerebellar artery or a vein. The fact that a small number of unsuspected tumors will be found in cases of typical "tic" has been cited as an advantage of the decompression procedure.

Unquestionably the posterior fossa procedure carries greater risk for the patient than percutaneous rhizotomy, as it is a major operation requiring skill in microsurgical technique. In the
TABLE 7

Previously Reported Results of Percutaneous Rhizotomy in Classical Trigeminal Neuralgia

\section{NUMBER OF}

PATIENTS

AUTHOR

FOLLOWED

\author{
FAILURE TO \\ RELIEVE \\ PAIN
}

\section{RECURRENT PAIN}

TIME OF FOLLOW-UP

Sweet and Wepsic

(1974)

125

Nugent and

Berry (1974)

Tew and Keller

(1977)

Siegfried (1977)

Apfelbaum (1977)
65

400

416

48
$9 \%$

$5 \%$

$1 \%$

$2 \%$

$12 \%$
$22 \%$

$5 \%$

$14 \%$

$4 \%$

$23 \%$
2.5-6 years

$1-41$ mont hs (average of 13 mos.)

$1-7$ years

8-57 months

1-36 months 
TABLE 8

Previously Reported Results of Microvascular Decompression In Classical Trigeminal Neuralgia

\section{AUTHOR}

Jannetta (1976)

Apfelbaum (1977)

Jannetta (1977)

Petty and

Southby (1977)

Kelly (1977)

Rhoton (1978)

Jannetta and

Zorub (1979)

Jannetta (1979)

most experienced hands (Jannetta, 1979), the mortality rate is $1 \%$. The reported incidence of serious complications is relatively low (Table 6). Specific risks include cerebellar infarction or hematoma, persisting gait ataxia or vertigo and dysfunction of adjacent cranial nerves. In a few patients, the fourth cranial nerve is at particular risk as it may be in close relationship to the trigeminal nerve, making its manipulation inevitable. Facial palsy and permanent hearing loss is possible.

Microvascular decompression has a high initial success rate (Table 8 ) which suggests that the etiological explanation is correct and that the treatment is effective. It is possible, however, that this initial success relates to the relatively minor but inevitable manipulation of the nerve during the procedure, particularly as the prosthesis is positioned. Jannetta (1977, 1979) believes the common causes of initial failure are either that a compressive lesion is missed or that the patient has unrecognized multiple sclerosis. In our three immediate failures, there was no convincing lesion in one patient, the causative lesion may have been missed in one, and no explanation can be given in the other as a convincing compressive lesion was found.

A comprehensive report of the long term results of the procedure is not yet available in the literature (Table 8 ).
NUMBER OF
PATIENTS
FOLLOWED

100

55

200

17

9

10

156

275

Jannetta (1976, 1977, 1979) and Jannetta and Zorub (1979) have reported variable results in various groups of patients with a delayed recurrence rate as high as $16 \%$. Apfelbaum (1977) reported a delayed recurrence rate of $24 \%$ with an average follow-up of only six months. We have experienced a $17 \%$ delayed recurrence rate with a longer follow-up averaging 28 months. Both Apfelbaum (1977) and ourselves have experienced a combined initial failure and recurrence rate of $30 \%$ with relatively short follow-up. This is a disturbingly high rate. None of our delayed recurrences suggested a slipped prosthesis clinically. These results raise the possibility that the etiological concept is not correct, or that the surgical treatment is in some way defective. Futher follow-up and reports of the long term experience of others are required to settle these points.

In summary, a totally safe, nondestructive and permanent surgical treatment for tic douloureux refractory to medical treatment has yet to be found. Percutaneous trigeminal rhizotomy has an established place, especially in the management of elderly or medically unfit patients because of its safety, but fails as an ideal procedure because of its destructive nature and high recurrence rate. Microvascular decompression has attracted considerable interest as it is directed at the

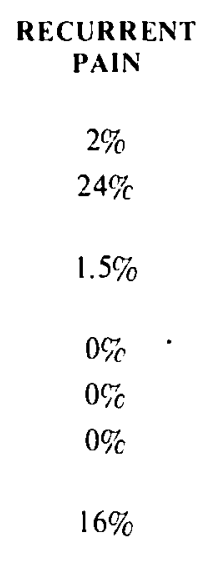

TIME OF FOLLOW-L'P

2-94 months

1-14 months (average of 6 mos.) not given maximum of 36 mos. maximum of 16 mos. maximum of 21 mos.

up to 6 years up to 13 years presumed cause of the pain and is nondestructive. The procedure carries definite risk, however, and the long term results are not yet known. It may prove to be the treatment of choice in younger patients who do not wish facial numbness and are willing to accept the inherent risks of such surgery.

\section{REFERENCES}

APFELBAUM, R.I.. (1977), A comparison of percutaneous radio-frequency trigeminal neurolysis and microvascular decompression of the trigeminal nerve for the treatment of tic douloureux. Neurosurgery $1: 16-21$.

BRETT. D.C., FERGUSON. G.G.. EBERS. G.C.. and PATY. D.W.. (1981). Percutaneous trigeminal rhizotomy in the treatment of trigeminal neuralgia secondary to multiple sclerosis. (In press)

DANDY. W.E., (1934). Concerning the cause of trigeminal neuralgia. Am. J. Surg. 24: 447455.

HAINES. S.J.. JANNETTA, P.J., and ZORUB. D.S.. (1980). Microvascular relations of the trigeminal nerve: an anatomical study with clinical correlation. J. Neurosurg. 52: 381386.

HARDY, D.G. and R HOTON, A.L. Jr. (1978). Microsurgical relationships of the superior cerebellar artery and the trigeminal nerve. J. Neurosurg. 49: 669-678.

JANNETTA, P.J.. (1976). Microsurgical approach to the trigeminal nerve for tic douloureux. Prog. Neurol. Surg. 7: 180-200.

JANNETTA. P.J. (1977). Treatment of trigeminal neuralgia by suboccipital and transtemtorial cranial operations. Clin. Neurosurg. 24: $538-$ 549. 
JANNETTA, P.J., (1979). Microsurgery of cranial nerve cross-compression. Clin. Neurosurg. 26: 607-615.

JANNETTA, P.J. and ZORUB, D.S., (1979). Microvascular decompression for trigeminal neuralgia. In, Surgery of the Posterior Fossa. Ed. Buckheit, W.A. and Truex, R.C., Raven Press, New York, pp 143-154.

KELLY, D.L., (1977). Posterior fossa neurovascular decompression for tic douloureux and hemifacial spasm. North Carolina Med. J. 38: 534-536.

KIRSCHNER, M., (1942). Die Behandlung der Trigeminusneuralgie (nach Erfahrungen an 1113 Kranken). Munchen Med. Wschr. 89: 235-239.

MENZEL, J., PIOTROWSKI, W., and PENZHOLZ, H. (1975). Long-term results of Gasserian ganglion electrocoagulation. J. Neurosurg. 42: 140-143.
MORLEY, J.P., (1977). The place of peripheral and subtemporal ablative operations in the treatment of trigeminal neuralgia (tic douloureux). Clin. Neurosurg. 24: 550-556.

NUGENT, G.R. and BERRY, B., (1974). Trigeminal neuralgia treated by differential percutaneous radiof requency coagulation of the Gasserian ganglion. J. Neurosurg. 40: 517-523.

ONOFRIO, B.M., (1975). Radiofrequency percutaneous Gasserian ganglion lesions: results in 140 patients with trigeminal pain. J. Neurosurg. 42: 132-139.

PETTY, P.G, and SOUTHBY, R. (1977). Vascular compression of lower cranial nerves: observations using microsurgery, with particular reference to trigeminal neuralgia. Aust. N.Z.J. Surg. 47: 314-320.

RHOTON, A.L. Jr. (1978). Microsurgical neurovascular decompression for trigeminal neuralgia and hemifacial spasm. J. Florida Med. Ass. 65: 425-428.
SIEGFRIED, J. (1977). 500 percutaneous thermocoagulations of the Gasserian ganglion for trigeminal pain. Surg. Neurol. 8: 126-131.

SWEET, W.H. and WEPSIC, J.G. (1974). Controlled thermocoagulation of trigeminal ganglion and rootlets for differential destruction of pain fibres. Part 1: trigeminal neuralgia. J. Neurosurg. 40: 143-156.

SWEET, W.H. (1976). Treatment of facial pain by percutaneous differential thermal trigeminal rhizotomy. Prog. Neurol. Surg. 7: 153-179.

TEW, J.M. Jr. and KELLER, J.T. (1977). The treatment of trigeminal neuralgia by percutaneous radiofrequency technique. Clin. Neurosurg. 24: 557-578.

TURNBULL, I.M. (1974). Percutaneous rhizotomy for trigeminal neuralgia. Surg. Neurol. 2: $385-389$. 